\title{
Immune Suppressive Effects of Tonsil-Derived Mesenchymal Stem Cells on Mouse Bone-Marrow-Derived Dendritic Cells
}

\author{
Minhwa Park, ${ }^{1}$ Yu-Hee Kim, ${ }^{1}$ Jung-Hwa Ryu, ${ }^{1}$ So-Youn Woo, ${ }^{1}$ and Kyung-Ha Ryu ${ }^{2}$ \\ ${ }^{1}$ Department of Microbiology, School of Medicine, Ewha Womans University, Seoul 158-710, Republic of Korea \\ ${ }^{2}$ Department of Pediatrics, School of Medicine, Ewha Womans University, Seoul 158-710, Republic of Korea \\ Correspondence should be addressed to So-Youn Woo; soyounwoo@ewha.ac.kr and Kyung-Ha Ryu; ykh@ewha.ac.kr
}

Received 21 November 2014; Revised 9 January 2015; Accepted 24 January 2015

Academic Editor: Armand Keating

Copyright (C) 2015 Minhwa Park et al. This is an open access article distributed under the Creative Commons Attribution License, which permits unrestricted use, distribution, and reproduction in any medium, provided the original work is properly cited.

\begin{abstract}
Mesenchymal stem cells (MSCs) are considered valuable sources for cell therapy because of their immune regulatory function. Here, we investigated the effects of tonsil-derived MSCs (T-MSCs) on the differentiation, maturation, and function of dendritic cells (DCs). We examined the effect of T-MSCs on differentiation and maturation of bone-marrow- (BM-) derived monocytes into DCs and we found suppressive effect of T-MSCs on DCs via direct contact as well as soluble mediators. Moreover, T cell proliferation, normally increased in the presence of DCs, was inhibited by T-MSCs. Differentiation of CD4 ${ }^{+} \mathrm{T}$ cell subsets by the DC-T cell interaction also was inhibited by T-MSCs. The soluble mediators suppressed by T-MSCs were granulocyte-macrophage colonystimulating factor (GM-CSF), RANTES, interleukin-6 (IL-6), and monocyte chemoattractant protein-1 (MCP-1). Taken together, T-MSCs exert immune modulatory function via suppression of the differentiation, maturation, and function of BM-derived DCs. Our data suggests that T-MSCs could be used as a novel source of stem cell therapy as immune modulators.
\end{abstract}

\section{Introduction}

Mesenchymal stromal cells (MSCs) have known regulatory effects on immune and inflammatory responses [1]. Furthermore, bone-marrow-derived MSCs (BM-MSCs) regulate the functions of immune cells such as T cells [2-4], dendritic cells (DCs), B cells, and natural killer cells [5]. Among these, DCs are the orchestrators of the immune response because of their function as antigen-presenting cells. We previously showed that BM-MSCs can inhibit DC maturation and motility [6]. Thus, because MSCs participate in the immune modulatory function of DCs, they might be useful as cell therapy agents for various autoimmune diseases. Although MSCs have a known immune modulatory effect on DC maturation and migration, their influence on antigen presentation function and recruitment of DCs has not been studied.

In a previous report, we confirmed that tonsil-derived stromal cells (T-MSCs) have characteristics of MSCs [7]. In comparison with BM-MSCs, adipose-derived (AD) MSCs have similar immunomodulatory effects [8]. Although ADMSCs reduced inflammatory and $\mathrm{T}$ cell responses via interleukin-10 (IL-10) secretion and induction of $\mathrm{T}_{\text {reg }}$ cells [9], the immunomodulatory effects of T-MSCs have not been characterized. Therefore, in this study we evaluated the immunomodulatory effects of T-MSCs on DC and characterized their mechanism of action.

\section{Materials and Methods}

2.1. Mice. Eight-week-old female Balb/c mice (OrientBio, Korea) were used. All procedures and protocols were approved by Ewha Womans University College of Medicine Animal Ethics Committee (ESM 11-0222). Mice were kept at $21^{\circ} \mathrm{C} \sim 23^{\circ} \mathrm{C}$ and $51 \% \sim 54 \%$ humidity with a $12 \mathrm{~h}$ light/dark cycle. Food and water were available ad libitum.

2.2. Harvest and Culture of T-MSCs. Tonsils were obtained with informed consent from patients undergoing tonsillectomy and Institutional Review Board approval (ECT 11-5302, Ewha Womans University, Mok-Dong Hospital, Seoul, Korea). Fresh palatine tonsils were washed five times with PBS, followed by mincing with blade and digested in RPMI 1640 medium containing $210 \mathrm{U} / \mathrm{mL}$ collagenase type I (Invitrogen) and $10 \mu \mathrm{g} / \mathrm{mL}$ DNase (Sigma-Aldrich, St. Louis, MO, 
USA) for $30 \mathrm{~min}$ at $37^{\circ} \mathrm{C}$. Following filtration through a cell strainer, the cells were washed twice in $20 \%$ normal human serum (PAA Laboratories $\mathrm{GmbH}$, Austria) containing RPMI 1640 medium and once with 10\% human serum/RPMI 1640. Mononuclear cells were obtained from cell suspension by Ficoll-Paque (GE Healthcare, Buckinghamshire, UK) density gradient centrifugation. The cells were plated at a density of $1 \times 10^{7}$ cells per $100 \mathrm{~mm}$ diameter in culture dishes in DMEM containing $10 \%$ fetal bovine serum (FBS) with antibiotics. After $24 \mathrm{~h}$, nonadherent cells were removed by pipetting and replenished with RPMI 1640 containing antibiotics and $10 \%$ FBS. For the following experiment, T-MSCs (passage 4) were precultured for $24 \mathrm{hrs}$ at $5 \times 10^{5}$ cells/well in a 6-well plate in RPMI 1640 supplemented with 10\% heatinactivated fetal bovine serum (FBS; Welgene, Korea) and 1\% penicillin/streptomycin [7].

2.3. Generation and Differentiation of BM-DCs. Female $\mathrm{Balb} / \mathrm{c}$ mice were sacrificed and $\mathrm{BM}$ was obtained from both femur and tibia. Femurs and tibias were flushed with $5 \mathrm{~mL}$ RPMI 1640, and red blood cells (RBCs) were lysed using ACK buffer $\left(10 \mathrm{x}, 1.5 \mathrm{M} \mathrm{NH}_{4} \mathrm{Cl}, 100 \mathrm{mM} \mathrm{KHCO}\right.$, and $10 \mathrm{mM}$ disodium EDTA). Cell pellets were resuspended and harvested at each well $2 \times 10^{6}$ cells in 6 -well cell culture plate with RPMI 1640 containing 10\% FBS and 1\% penicillin/streptomycin. DCs were induced to differentiate by the addition of recombinant mouse GM-CSF (rmGM-CSF, R\&D Systems, Minneapolis, MN, USA) (20 ng/mL) every 3 days and lipopolysaccharide (LPS) $(1 \mu \mathrm{L} / \mathrm{mL}$, Sigma, St. Louis, MO, USA) on day 10. After another $48 \mathrm{hrs,} \mathrm{cells} \mathrm{and} \mathrm{medium}$ were collected for further assays.

2.4. Coculture of BM-DCs with T-MSCs. In order to prevent contact between BM-DCs and T-MSCs, we used a transwell plate with a $0.4 \mu \mathrm{m}$ pore size polycarbonate membrane (Corning, Acton, MA). BM-DCs and T-MSCs were placed in the upper and lower chambers of the plate (ratio $5: 1$ ), respectively, and were cultured in RPMI 1640 medium with $10 \% \mathrm{FBS}, 1 \%$ penicillin, and $20 \mathrm{ng} / \mathrm{mL} \mathrm{rmGM}-\mathrm{CSF}$. LPS $(1 \mu \mathrm{L} / \mathrm{mL})$ was added to the upper chamber on day 10 to induce maturation of BM-DCs.

2.5. Flow Cytometry. For phenotyping, cells were incubated with the following fluorochrome-conjugated antibodies at final concentration of $2 \mathrm{ug} / \mathrm{mL}$ : FITC-anti-mouse CD11b (M1/70, Rat IgG 2 , eBiosciences, San Diego, CA), PE-antimouse CD11c (HL3, Hamster IgG ${ }_{1}$, BD Biosciences, Franklin Lakes, NJ), APC-anti-mouse CD11c (N418, Hamster IgG, BioLegend, San Diego, CA), PerCP-anti-mouse CD80 (16-1 OA1, Hamster IgG 2 , BD Biosciences), PE-anti-mouse CD86 (GL1, Rat $\operatorname{IgG}_{2 \mathrm{a}}$, BD Biosciences), PE-anti-mouse CD14

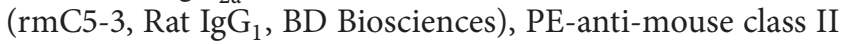
major histocompatibility complex (MHC) (2G9, Rat $\operatorname{IgG}_{2 \mathrm{a}}$, BD Biosciences), and PE-anti-mouse CCR7 (4B12, Rat $\operatorname{IgG}_{2 \mathrm{a}}$, R\&D Systems). For controls, no stained cells were used. Cells were centrifuged at $300 \times \mathrm{g}$ for $5 \mathrm{~min}$ at RT, washed, and fixed in $1 \%$ paraformaldehyde in phosphate buffered saline (PBS).
For intracellular staining, cells were fixed in $4 \%$ paraformaldehyde (PFA) in PBS for 20 min on ice and then washed with $20 \%$ permeabilization buffer $(0.5 \%$ saponin, $1 \%$ bovine serum albumin (BSA) in PBS) plus $0.5 \%$ FBS in PBS. Cells were resuspended and incubated with the following fluorochrome-conjugated antibodies for $30 \mathrm{~min}$ on ice: FITCanti-mouse CD4 (RM4.5, Rat IgG Ia , BD Biosciences), APCanti-mouse interferon gamma (IFN- $\gamma$ ) (XMG1.2, Rat IgG , $_{1}$ BioLegend), PE-anti-mouse interleukin-4 (IL-4) (11B11, Rat $\mathrm{IgG}_{1}, \mathrm{BD}$ Biosciences), and PE-anti-mouse interleukin-17A (IL-17A) (TC11-18H10.1, Rat $\operatorname{IgG}_{1}$, BioLegend). Following staining, cells were washed, resuspended in $0.5 \%$ FBS in PBS, and analyzed by flow cytometry with Cell Quest software (BD Biosciences).

2.6. Isolation of $C D 4^{+}$T Cells. Spleens were obtained from 8week-old female Balb/c mice and were manually disrupted in 5 mL RPMI1640 medium. Cell suspensions were washed and resuspended with $600 \mu \mathrm{L}$ MACS sorting buffer (containing $0.5 \%$ BSA, 2 mM EDTA in PBS, pH 7.2) followed by addition of anti-CD4 or anti-CD3 microbead solution $\left(10 \mu \mathrm{L}\right.$ per $10^{7}$ cells). Cells were incubated on ice for $15 \mathrm{~min}$ on ice, washed, and resuspended in $1 \mathrm{~mL}$ sorting buffer. Cells were separated using a MACS magnetic column (Miltenyi Biotec, Auburn, CA, USA) according to the manufacturer's protocol. Separated cells were stained with PE-conjugated anti-mouse CD4 antibody (GK 1.5, Rat $\operatorname{IgG}_{2 \mathrm{~b}}$, BioLegend) and analyzed by flow cytometry to determine the purity of the cell population.

2.7. T Cell Proliferation and $C D 4^{+}$T Subset Differentiation. To measure proliferation, $2 \times 10^{8}$ cells were stained with $5 \mu \mathrm{M}$ carboxyfluorescein succinimidyl ester (CFSE, Invitrogen, Carlsbad, CA, USA) for $5 \mathrm{~min}$ at room temperature (RT); then $1 \mathrm{~mL}$ FBS was added to stop the reaction. Cells were washed three times in RPMI 1640 with $10 \%$ FBS and transferred to a 6 -well culture plate $\left(2 \times 10^{6}\right.$ cells/well). T-MSCs or BM-DCs were added and cultures were incubated for $48 \mathrm{hrs}$. For $\mathrm{T}$ cell stimulation, $5 \mathrm{ug} / \mathrm{mL}$ each of LEAF purified anti-

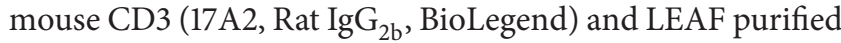
anti-mouse CD28 (37.51, Syrian Hamster IgG, BioLegend) antibodies were diluted in RPMI 1640 with $10 \%$ FBS and antibiotics and added to the cells. Cell numbers are $4 \times 10^{5}$ cells/well for T-MSCs, for $2 \times 10^{6}$ cells/well BM-DCs, and for $2 \times 10^{6}$ cells/well T cells. After $48 \mathrm{hrs}$, cells were collected for flow cytometric analysis and supernatants were assayed by Cytokine Array.

2.8. Cytokine Array. Collected culture medium and Human Cytokine Array C1 Kit (RayBiotech, Norcross, GA, USA) components were equilibrated to RT and the assay was performed according to the manufacturer's instructions. The developed membrane was analyzed by a chemiluminescence imaging system (LAS-3000, Fujifilm, Japan).

2.9. Statistical Analysis. Data are expressed as the mean \pm standard error of the mean (SEM). One-way or two-way ANOVA was used for group analysis, and Student's $t$-test was used to identify statistically significant differences in 


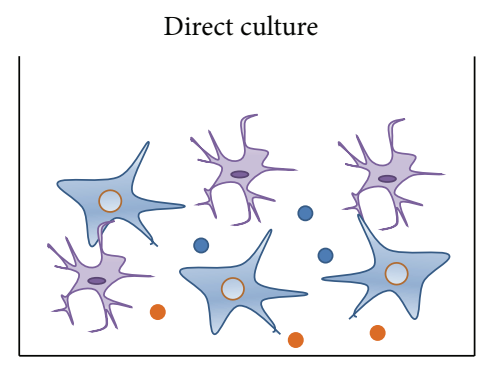

th BMC-derived DC

is T-MSC

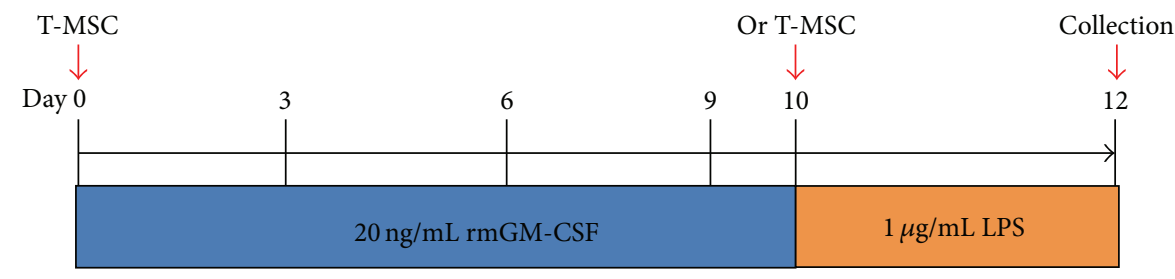

Mouse: 8-weeks-old female Balb/c

BMC: $2 \times 10^{6}$ cells/well

T-MSC: $4 \times 10^{5}$ cells/well

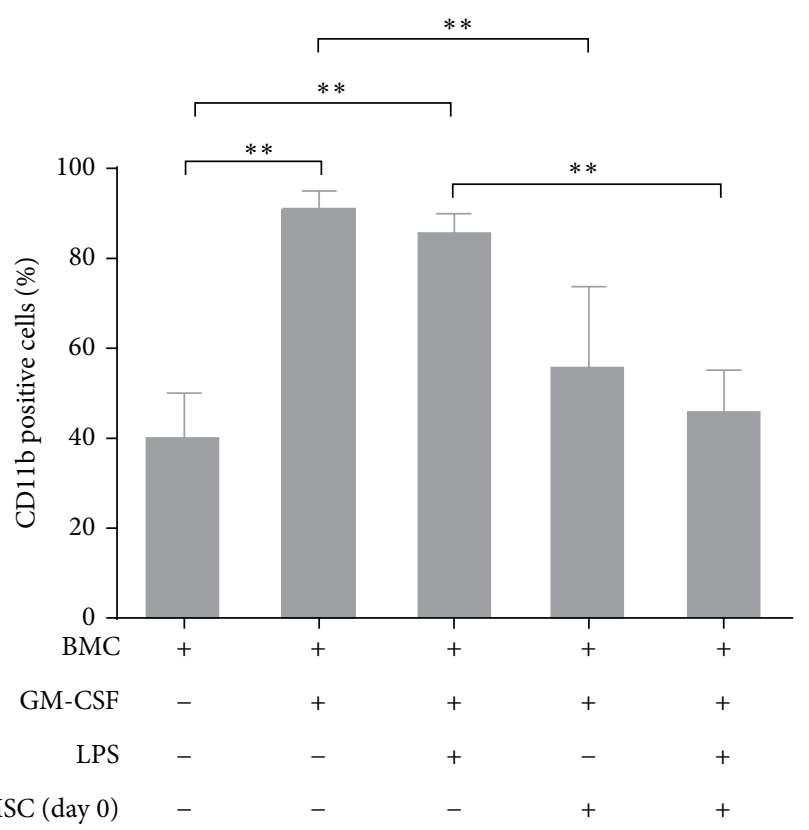

(b)
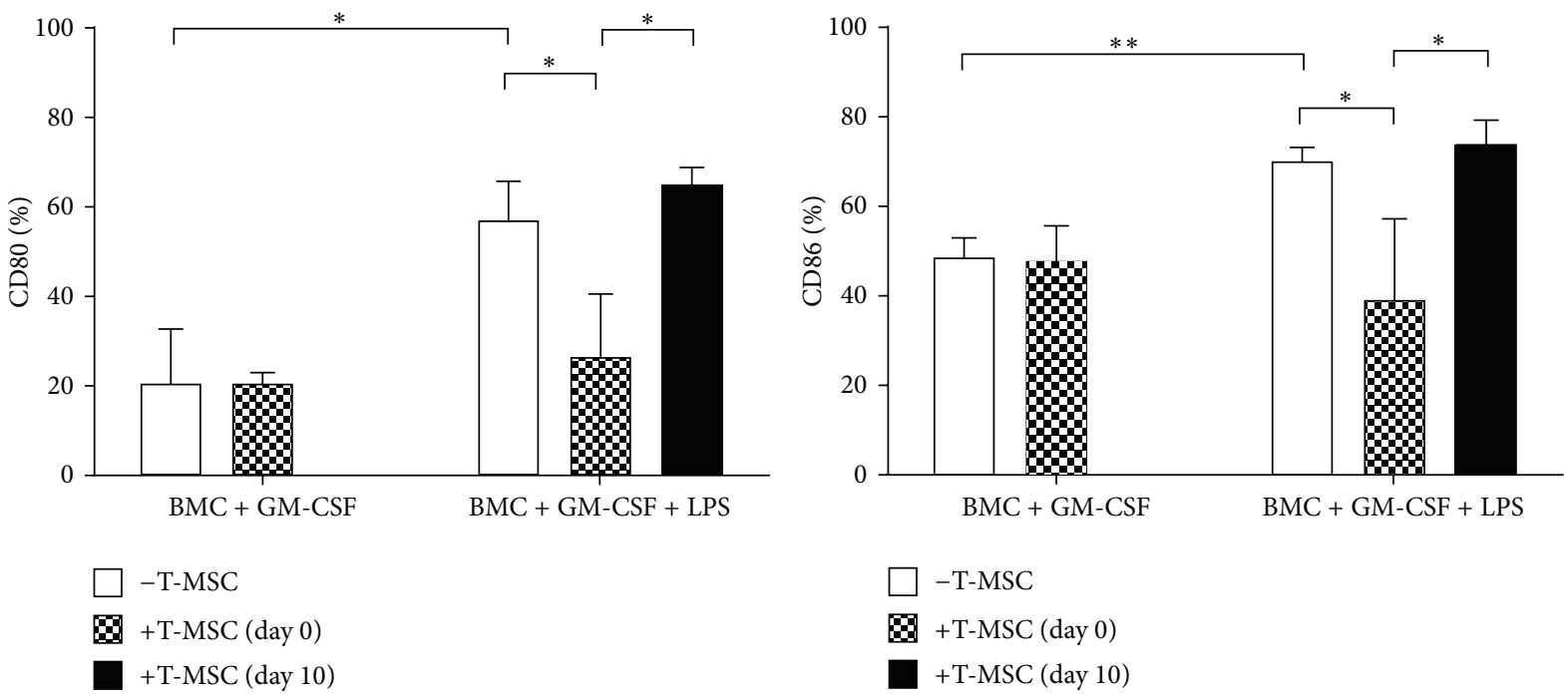

FIgURe 1: Continued. 

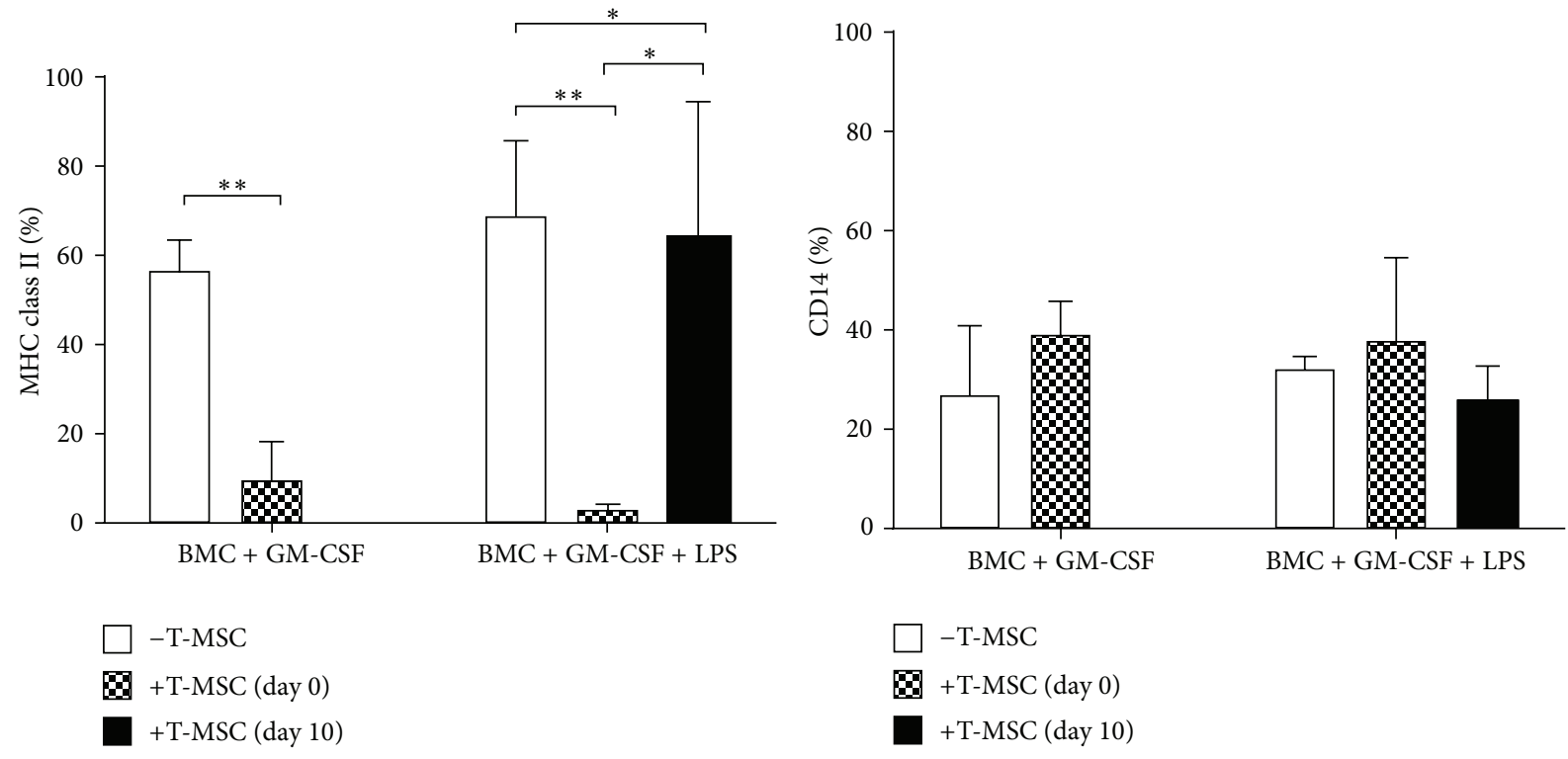

(c)

FIGURE 1: T-MSCs inhibit differentiation and maturation of DCs under coculture conditions. Bone-marrow- (BM-) derived monocytes (BMCs) isolated from 8-week-old BALB/c mice were incubated with of granulocyte-macrophage colony-stimulating factor (GM-CSF) $(20 \mathrm{ng} / \mathrm{mL})$ for 12 days to induce differentiation into dendritic cells (DCs). (a) Lipopolysaccharide (LPS) $(1 \mu \mathrm{g} / \mathrm{mL})$ was added for the last 2 days to induce DC maturation. (b) GM-CSF treatment induced expansion of CD11b ${ }^{+}$cells $\left({ }^{* *} P<0.01\right)$. (c) Tonsil-derived MSCs (T-MSCs) added at day 0 , but not at day 10 , inhibited upregulated expression of $\mathrm{CD} 80\left({ }^{*} P<0.05\right)$ and $\mathrm{CD} 86\left({ }^{* *} P<0.01\right)$ on mature DCs by direct contact. Upregulated major histocompatibility complex (MHC) class II expression on immature $\left({ }^{* *} P<0.01\right)$ and mature DCs $\left({ }^{* *} P<0.01\right)$ was reduced by T-MSCs, but CD14 expression was not affected.

staining (at $P<0.05$ ). Statistical analyses were performed using GraphPad Prism Software (GraphPad Software Inc., San Diego, CA).

\section{Results}

3.1. T-MSCs Inhibited Differentiation of $C D 11 b^{+}$DCs from BMCs under Coculture Conditions. Mouse BM cells (BMCs) were cultured with rmGM-CSF $(20 \mathrm{ng} / \mathrm{mL}$ ) for 10 days to induce differentiation into immature DCs, followed by the addition of LPS for 48 hrs to induce DC maturation. T-MSCs $\left(4 \times 10^{5}\right.$ cells/well $)$ were added to culture plates providing cell-to-cell contact on either day 0 or day 10 of BMC culture

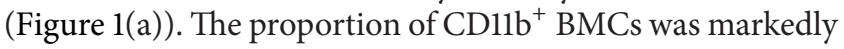
increased from $38.9 \pm 4.8 \%$ to $90.7 \pm 1.9 \%(P<0.05)$ with the addition of GM-CSF $(20 \mathrm{ng} / \mathrm{mL})$ with or without LPS for 10 days (Figure 1(b)). However, the addition of T-MSCs on day 0 inhibited $\mathrm{CD} 11 \mathrm{~b}^{+}$cell expansion $(55.1 \pm 8.3 \%)$, and this effect was not affected by the addition of LPS $(57.7 \pm 8.9 \%)$. Thus, TMSCs inhibited differentiation of BMC-derived DCs by GMCSF under cell-to-cell contact conditions (Figure 1(b)).

LPS stimulation increased the expression of the costimulatory molecules CD80 (56.8 $\pm 5.2 \%)$, CD86 (69.7 $\pm 3.4 \%)$, and class II MHC $(64.5 \pm 17.31 \%)$ on DCs; however, the proportion of $\mathrm{CD} 14^{+}$cells did not change. In contrast, the addition of T-MSCs from day 0 inhibited the upregulated expression of CD80 and CD86 induced by LPS but did not affect class II MHC expression. In addition, when T-MSCs were added from day 10, there was no inhibitory effect on the expression of the costimulatory molecules (Figure 1(c)). Therefore, T-MSCs likely inhibit BM-DC maturation as evidenced by the reduced expression of costimulatory molecules and class II MHC under cell contact conditions.

3.2. T-MSCs Inhibited Differentiation and Maturation of $C 11 b^{+}$DCs from BMCs under Transwell Conditions. Using the transwell culture plate, we investigated whether the ability of T-MSCs to inhibit DC differentiation required cell contact or was mediated through soluble factors (Figure 2(a)). TMSCs inhibited the expansion of $\mathrm{CD}_{11}{ }^{+}$cells in the BMDCs induced by GM-CSF, with or without LPS stimulation (Figure 2(b)). With the addition of T-MSCs from day 0 , expression of CD86 and class II MHC was decreased as well, irrespective of LPS stimulation (Figure 2(c)).

3.3. T-MSCs Inhibited DC-Mediated T Cell Proliferation and $\mathrm{CD}^{+} \mathrm{T}$ Cell Differentiation. In order to determine the effect of T-MSCs cocultured with BM-DCs on T cell proliferation, we isolated $\mathrm{T}$ cells from mouse spleens and labeled them with CFSE to measure cell division. As a control group, we also cultured $\mathrm{CD} 4^{+} \mathrm{T}$ cells with T-MSCs or with BM-DCs alone (Figure 3(a)). Proliferating T cells, represented as peaks of decreasing CFSE intensity, were reduced from $22.99 \%$ to $5.3 \%$ after the addition of T-MSCs to the culture (Figure 3(b)). Therefore, $22.99 \%$ of $\mathrm{CD}^{+}{ }^{+} \mathrm{T}$ cells cultured with BM-DCs and stimulated with anti-CD3/anti-CD28 divided once, but 

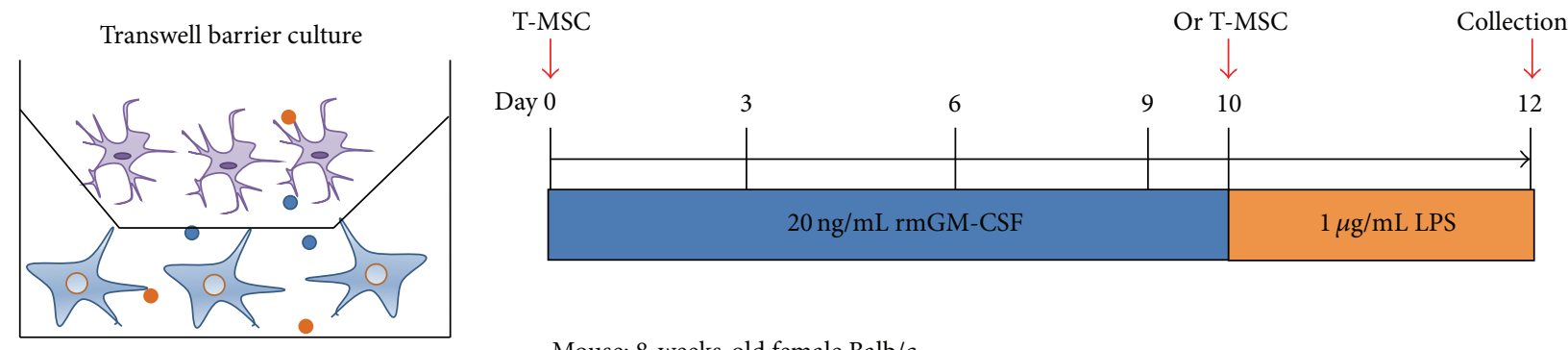

Mouse: 8-weeks-old female Balb/c

t]

BMC: $2 \times 10^{6}$ cells/well

T-MSC: $4 \times 10^{5}$ cells/well

(a)

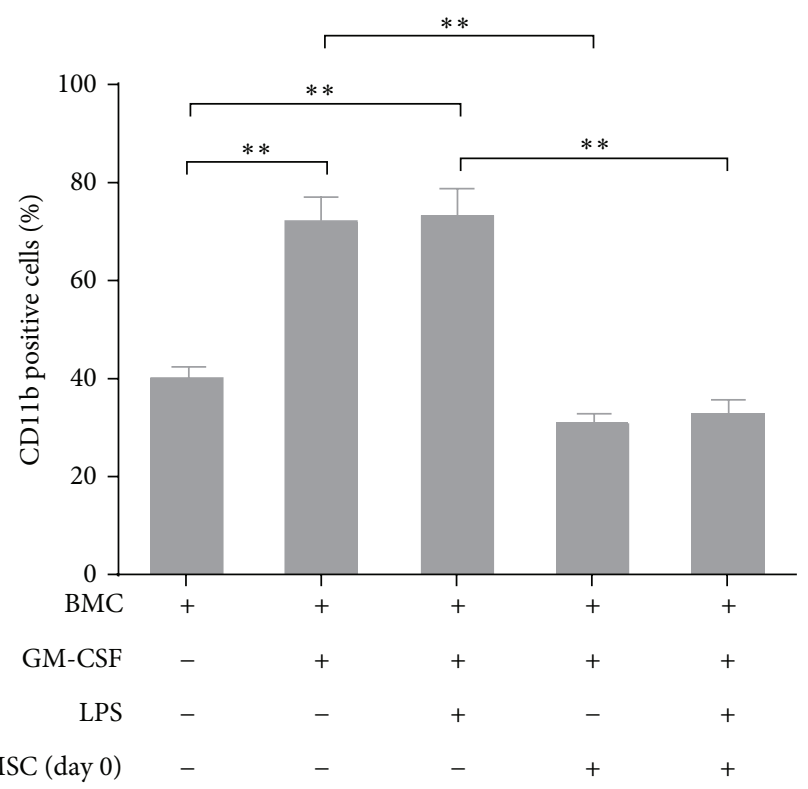

(b)
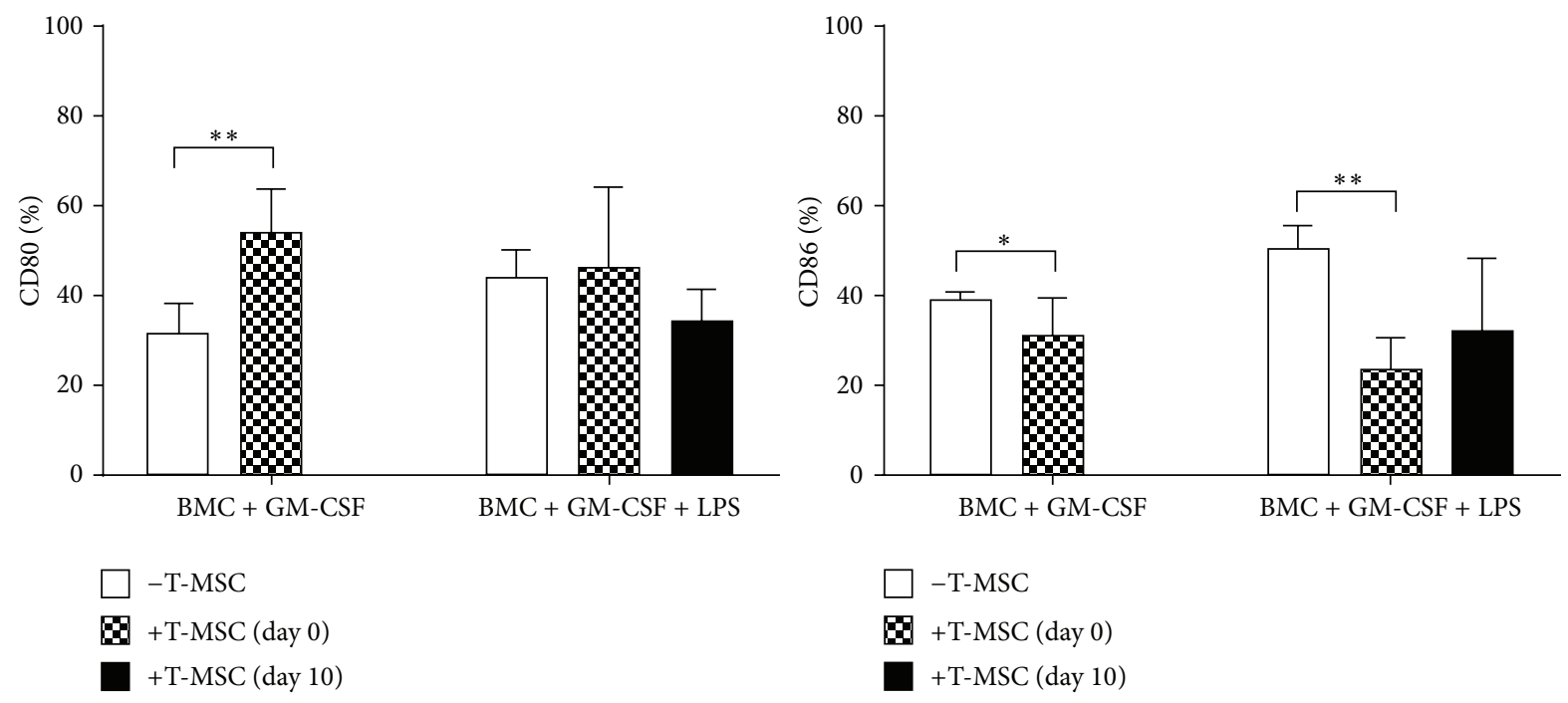

Figure 2: Continued. 

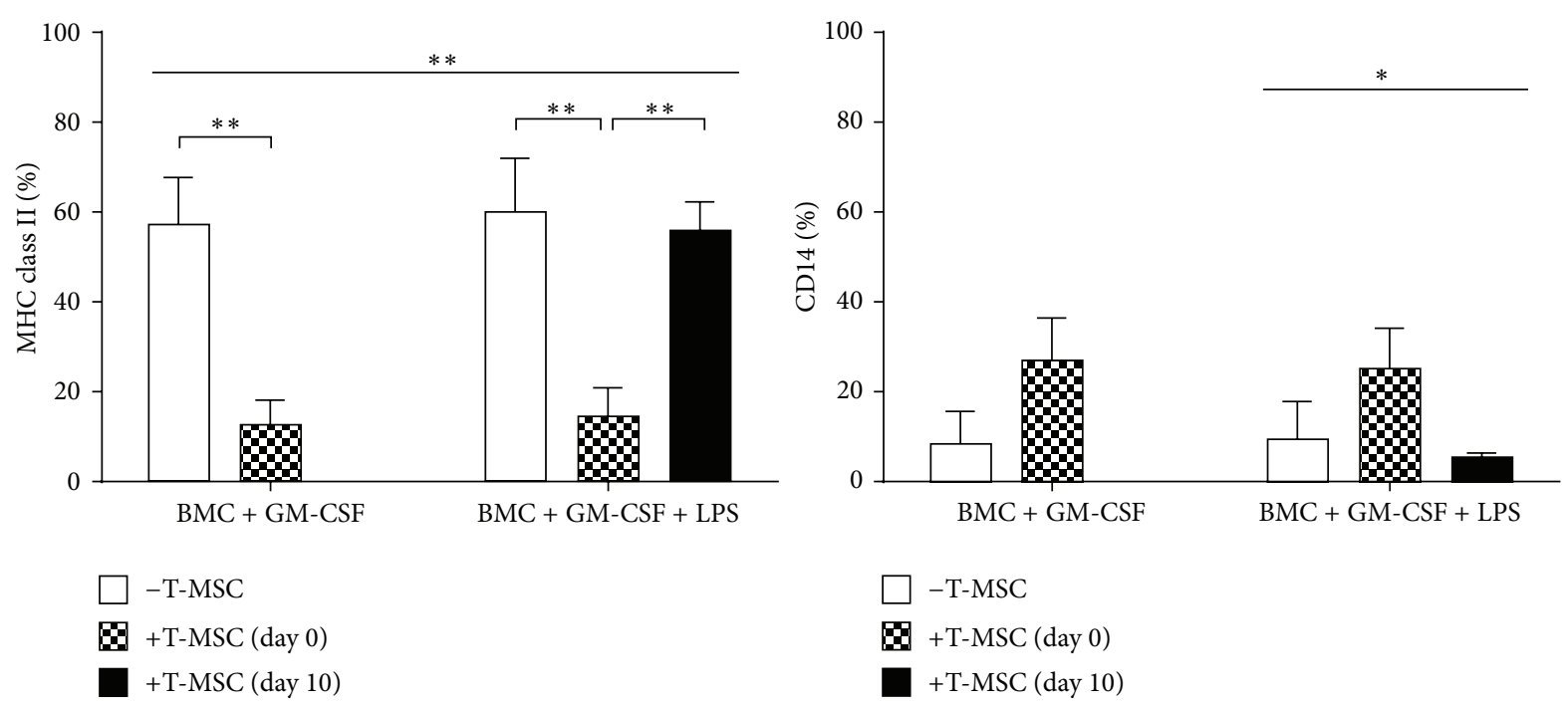

(c)

Figure 2: T-MSCs inhibit differentiation and maturation of DCs by secretion of soluble factors. (a) BMCs and T-MSCs were cultured in a transwell plate and BMCs were induced to differentiate into DCs by GM-CSF. (b) BMCs differentiation into CD11b ${ }^{+}$cells was inhibited by T-MSCs added at day $0\left({ }^{* *} P<0.01\right)$. (c) CD86 expression on mature DCs was significantly downregulated by T-MSCs $\left({ }^{* *} P<0.01\right)$. Similar to the coculture condition, MHC class II expression on immature and mature DCs was inhibited by factors secreted from T-MSCs $\left({ }^{* *} \mathrm{P}<0.01\right)$. CD14 expression by T-MSCs showed a trend toward increase, but it was not significant.

upon coculture with T-MSCs from day 0 , cell division was decreased to $5.30 \%$ (Figure 3(b)).

To evaluate the differentiating capacity of $\mathrm{CD} 4^{+} \mathrm{T}$ cell with BM-DCs, we isolated $\mathrm{CD} 4^{+} \mathrm{T}$ cells from mouse spleen and cocultured them with BM-DCs and anti-CD3/antiCD28 stimulation, with or without T-MSCs. After $48 \mathrm{hrs}$, we collected the cells and stained for flow cytometry analysis. We found that the percentage of $\mathrm{CD} 4^{+} \mathrm{INF}-\gamma^{+}\left(\mathrm{T}_{\mathrm{H}} 1\right.$ cell), $\mathrm{CD}^{+} \mathrm{IL}^{-} 4^{+}\left(\mathrm{T}_{\mathrm{H}} 2\right.$ cell), and CD4 $4^{+} \mathrm{IL}_{17 \mathrm{~A}^{+}}\left(\mathrm{T}_{\mathrm{H}} 17\right)$ cells was increased after coculture with BM-DCs and stimulation with anti-CD3/anti-CD28 antibodies. However, when cocultured with T-MSC-preconditioned BM-DCs, the proportions of differentiated $\mathrm{T}$ cells were reduced (Figure 3(c)).

3.4. T-MSCs Modulate Cytokine Secretion from Mature DCs. We analyzed the BM-DC secretome upon T cell stimulation using the Cytokine Array Kit (Figure 4(a)). We found that GM-CSF, growth-regulated oncogene- $\alpha$ (GRO- $\alpha$, also called CXCL1) regulated on activation, normal $\mathrm{T}$ cell expressed and secreted RANTES (also called CCL5), interleukin-8 (IL-8, also called CXCL8), IL-6, MCP-1 (also called CCL2), monocyte chemoattractant protein-2 (MCP-2, also called CCL8), and monocyte chemoattractant protein-3 (MCP-3, also called CCL7) were increased by $\mathrm{T}$ cell stimulation (Figure 4(b)). Among these cytokines, GM-CSF, IL-6, RANTES, and MCP-1 recruit immune cells such as DCs; these cytokines were significantly decreased upon the addition of T-MSCs. Thus, TMSCs inhibited the secretion of inflammation-related cytokines by DCs that are normally induced by $\mathrm{T}$ cell stimulation (Figure 4(c)).

\section{Discussion}

In this study, we confirmed that T-MSCs inhibited the differentiation of BM-DCs induced by GM-CSF and also inhibited the maturation of BM-DCs. We found that T-MSCs suppressed the maturation of BM-derived DCs via direct contact as well as through secretion of soluble factors. Moreover, TMSCs inhibited BM-DC-induced proliferation and differentiation of $\mathrm{CD} 4^{+} \mathrm{T}$ cells.

DCs play a central role in the initiation and regulation of immune responses to foreign as well as self-antigens. DCs have potent antigen presenting function and can induce $\mathrm{CD}^{+}{ }^{+} \mathrm{T}$ cell activation and differentiation. Several DC subsets participate in various immune functions and, among these various types of DC subsets, monocyte-derived DCs, which are associated with inflammation and infection, have been actively studied [10]. When naïve $\mathrm{CD} 4^{+} \mathrm{T}$ cells from mouse spleens interact with mature DCs (mDCs), secretion of GMCSF, IL-6, MCP-1, and RANTES is significantly decreased when the $\mathrm{T}$ cells are cocultured with T-MSC. The ability of T-MSC to inhibit RANTES secretion from T cells likely contributes to the prevention of binding between DC and $\mathrm{T}$ cells, which might lead to decreased immune stimulatory effect of BM-DCs. Because GM-CSF is considered a key factor for the differentiation of monocytes into inflammatory DCs [11], decreased GM-CSF under T-MSCs coculture possibly might block DC differentiation. In addition, TMSCs inhibit differentiation of T cell subsets, which might be caused by the interruption of DC and T cell signals due to downregulated expression of class II MHC molecule 


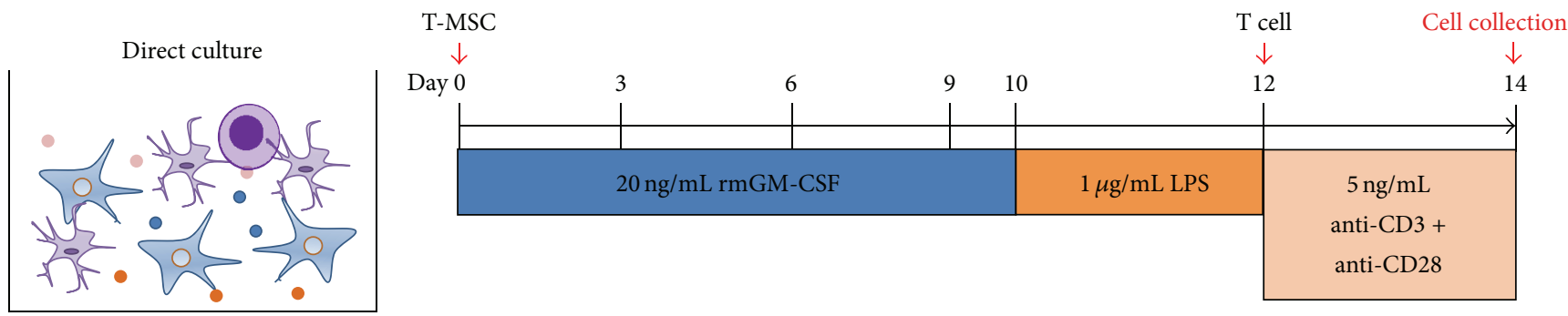

th BMC-derived DC

Mouse: 8-weeks-old female Balb/c

BMC: $2 \times 10^{6}$ cells/well

T-MSC: $4 \times 10^{5}$ cells/well

T-cell: $2 \times 10^{6}$ cells/well

(a)

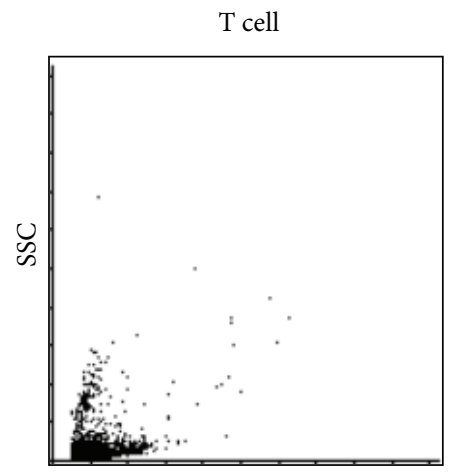

FSC

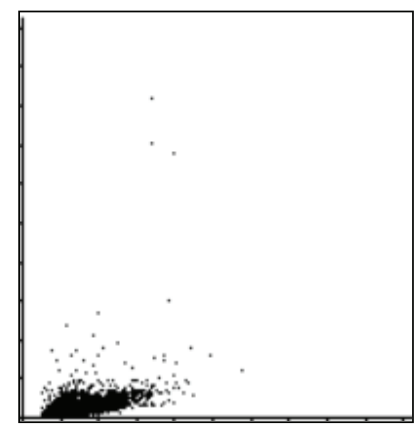

FSC

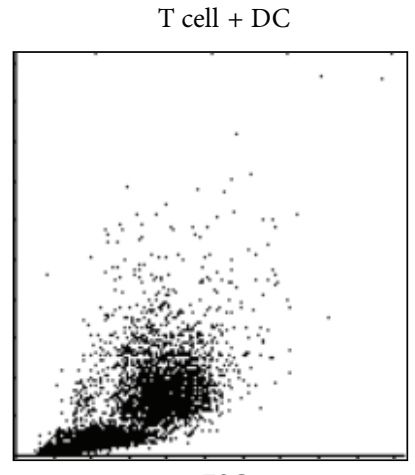

FSC
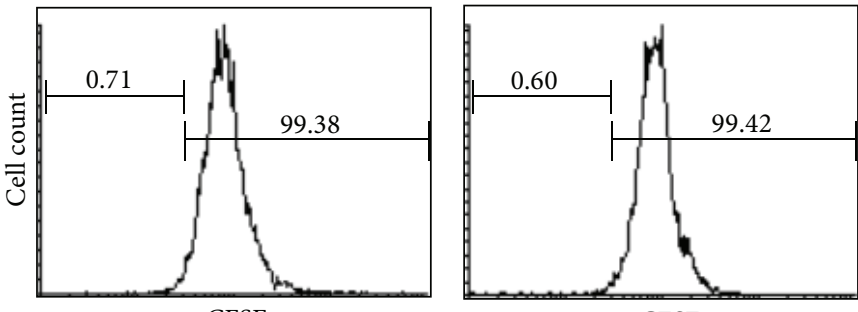

CFSE

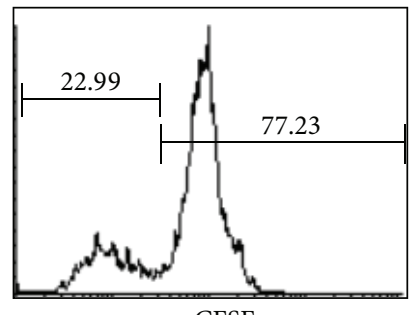

CFSE

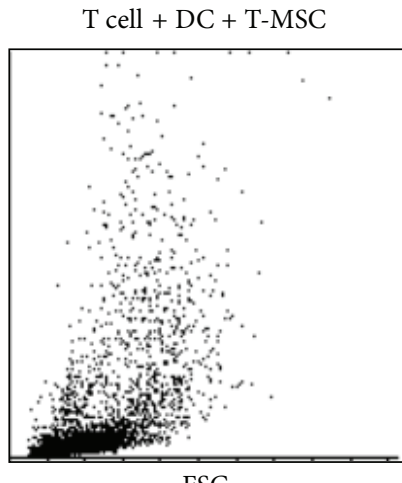

FSC

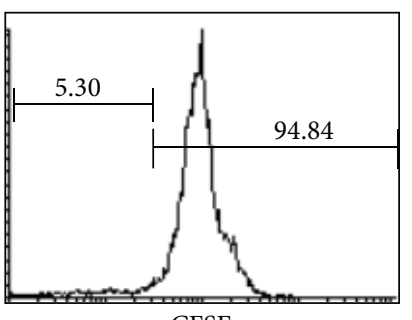

CFSE

(b)
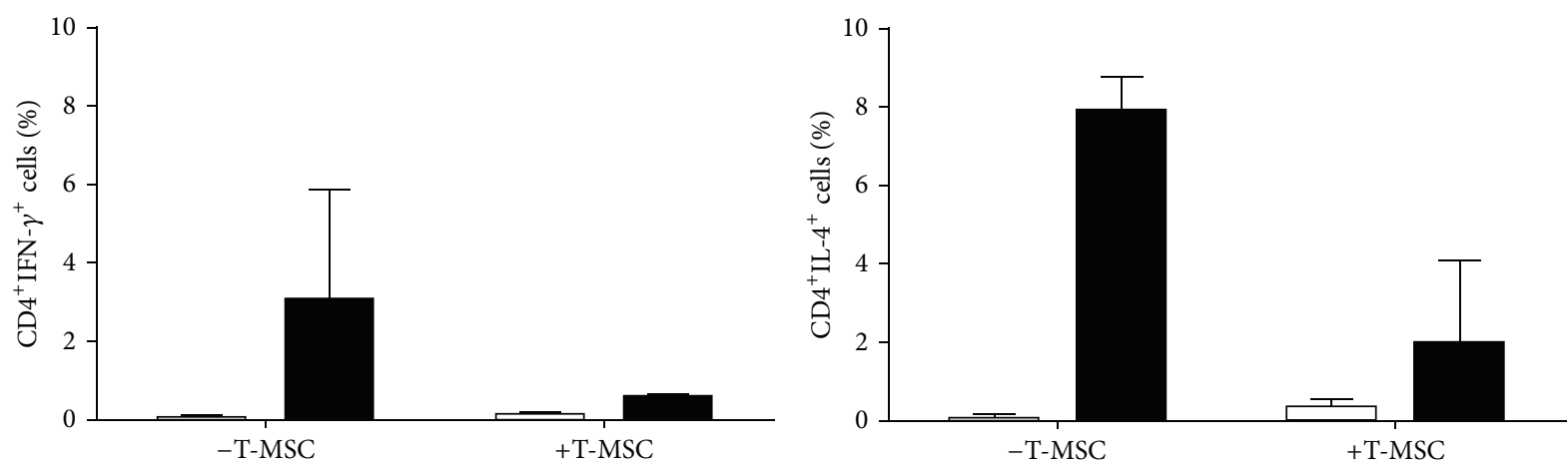

$\square-\mathrm{T}$ cell

$\square-\mathrm{T}$ cell

$+\mathrm{T}$ cell with stim.

$+\mathrm{T}$ cell with stim.

Figure 3: Continued. 


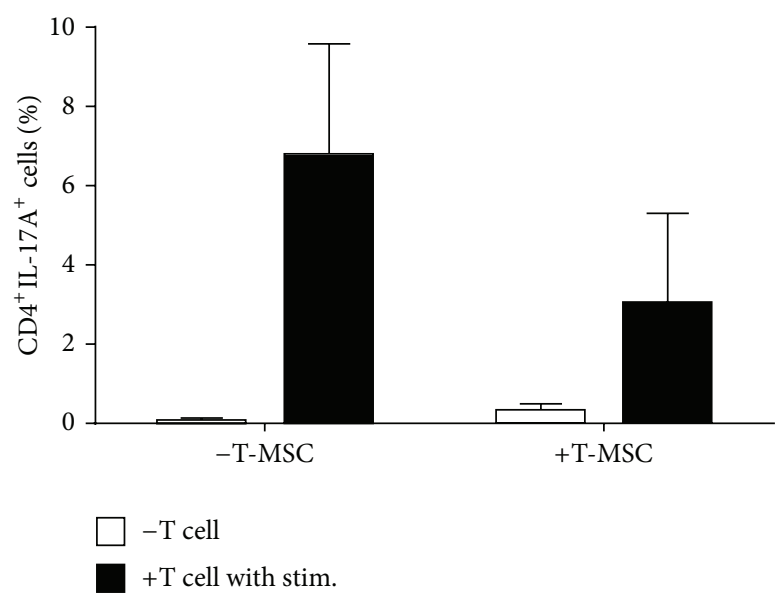

(c)

Figure 3: T-MSCs inhibit DC-mediated $\mathrm{T}$ cell proliferation and differentiation of the $\mathrm{CD} 4^{+} \mathrm{T}$ cell subset. (a) T cells were isolated from mouse spleens (BALB/c, 8-week-old, female) using MACS. (b) T cells were cocultured with mature DCs in the presence or absence of TMSCs, and differentiation into $\mathrm{CD} 4^{+} \mathrm{T}$ cell subsets was induced using anti-CD3 and anti-CD28 antibodies. T cell numbers were increased upon coculturing with mature DCs. In the presence of T-MSCs, however, T cell proliferation was inhibited by $80 \%$. (c) Differentiation into Th1, Th2, and Th17 cells also was decreased upon addition of T-MSCs.

expression on DC. Recently, the focus of MSC investigations has been on modulation of immune function using natural killer cells [12], T cells $[13,14]$, B cells $[15,16]$, DCs [17-19], and macrophages $[20,21]$ with the connection between immune cells and MSCs shown as having a major role in both innate and adaptive immunity. MSCs have been demonstrated to inhibit the maturation of monocyte-derived DCs by downregulating expression of class II $\mathrm{MHC}$ and costimulatory molecules [22]. The mechanism of MSC-induced inhibition of DC differentiation appears to be mediated by soluble factors, such as prostaglandin $\mathrm{E}_{2}\left(\mathrm{PGE}_{2}\right)$, which is secreted upon cell-to-cell contact [23]. Moreover, another mechanism used by MSCs to inhibit differentiation and maturation of DCs is production of IL-6 [24]. Prostaglandin $E_{2}$ inhibits fungus antigen-induced interferon regulatory factor 4 (IRF4) translation [25] and IRF4 plays an important role in class II MHC expression on CD11b ${ }^{+}$DCs [26]. Prostaglandin $\mathrm{E}_{2}$ and IL- 6 produced by T-MSC may play an important role in the inhibition of MHC class II expression on DC.

There has been a focus on MSCs derived from various sources in order to avoid the ethical stigma associated with embryonic stem cells [27]. In addition, the prohibitive costs and low success rates of induced pluripotent stem cells make MSCs a more attractive prospect for immune therapy [28]. However, BM-MSCs are difficult to obtain [29] and BM yields comparatively fewer MSCs as compared to cord blood or amniotic fluid [30]. Therefore, a new source of MSCs devoid of these disadvantages is greatly needed. Hence, our group's focus has been on T-MSCs, which have the capacity to differentiate into cells of various types and did not show dominant growth in mixed-culture from multiple donors [7]. Tonsillectomy was performed about 40,000 per year in Korea and mostly bilateral palatine tonsils were removed and discarded after the surgery. On our experiment, we used onethird volume of tonsils for the preparation of mononuclear cells and we usually got $8-10 \times 10^{8}$ cells. According to yields of cells, if we isolate mononuclear cells from bilateral tonsils from a person, we can get $6 \times 10^{10}$ cells and this corresponds to the number of cells transplantable for a person. In this paper, we studied the role of T-MSCs in the differentiation, maturation, and antigen presentation of monocytederived DCs. Mouse BM-derived DCs induced by GM-GSF expressing CD11b. LPS-stimulated BM-DCs (mature DCs) showed higher expression of CD80, CD86, and class II MHC molecules compared to DCs not stimulated with LPS. However, the T-MSC-pretreated DCs showed low expression of these markers. Cocultures of DC and T-MSC inhibited DC differentiation. We investigated whether or not the inhibitory effect of T-MSCs on DC was mediated through direct contact or via secreted factor(s). To make this determination, we used a transwell barrier method, which prohibits direct contact between T-MSCs and BM-DCs. We also examined DC maturation by analyzing cell phenotypes upon coculture with T-MSCs from day 0 or day 10 . We found that only TMSCs added from day 0 inhibited DC maturation and CD $4^{+}$ $\mathrm{T}$ cell proliferation. However, $\mathrm{CD}_{11 \mathrm{~b}^{+}}$cell expansion and CD86 upregulation by LPS stimulation were inhibited by TMSCs. Interestingly, CD86 and class II MHC molecules were also significantly reduced in immature DCs (i.e., without LPS stimulation). Thus, these T-MSCs exerted immune regulatory functions that are similar to MSCs derived from other sources and are mediated by soluble factors.

\section{Conclusions}

This is the first report demonstrating that T-MSCs have an immunoregulatory function: inhibition of DC maturation 


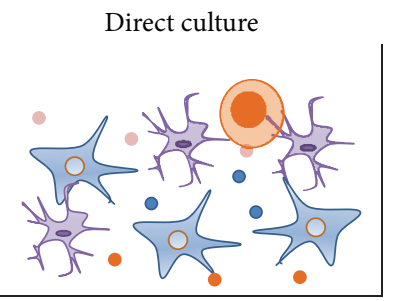

T-MSC

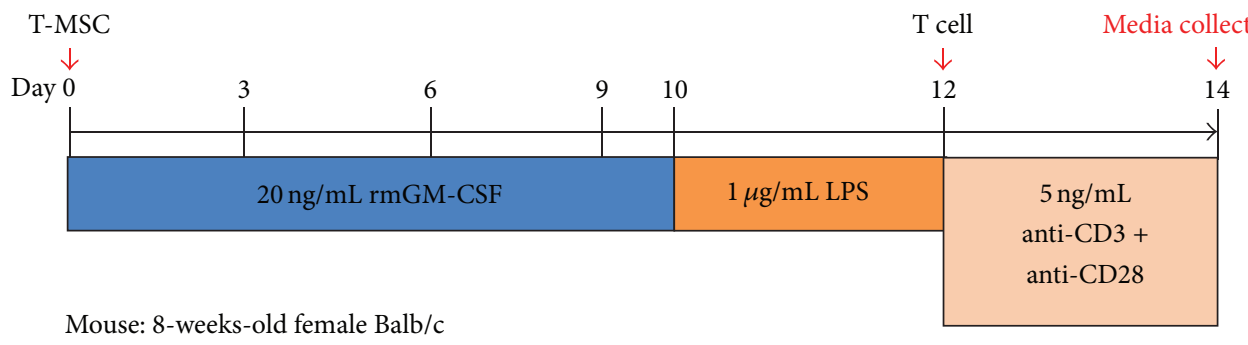

पर

BMC: $2 \times 10^{6}$ cells/well

T-MSC: $4 \times 10^{5}$ cells/well

T cell: $2 \times 10^{6}$ cells/well

(a)

\begin{tabular}{|c|c|c|c|c|c|c|c|}
\hline POS & POS & NEG & NEG & G-CSF & GM-CSF & GRO & GRO- $\alpha$ \\
\hline POS & POS & NEG & NEG & G-CSF & GM-CSF & GRO & GRO- $\alpha$ \\
\hline IL-1 $\alpha$ & IL-2 & IL-3 & IL-5 & IL-6 & IL-7 & IL-8 & IL-10 \\
\hline IL-1 $\alpha$ & IL-2 & IL-3 & IL-5 & IL-6 & IL-7 & IL-8 & IL-10 \\
\hline IL-13 & IL-15 & IFN- $\gamma$ & MCP-1 & MCP-2 & MCP-3 & MIG & RANTES \\
\hline IL-13 & IL-15 & IFN- $\gamma$ & MCP-1 & MCP-2 & MCP-3 & MIG & RANTES \\
\hline TGF- $\beta 1$ & TNF- $\alpha$ & TNF- $\beta$ & Blank & Blank & Blank & Blank & POS \\
\hline TGF- $\beta 1$ & TNF- $\alpha$ & TNF- $\beta$ & Blank & Blank & Blank & Blank & POS \\
\hline
\end{tabular}

T cell without stim.

T cell with stim.

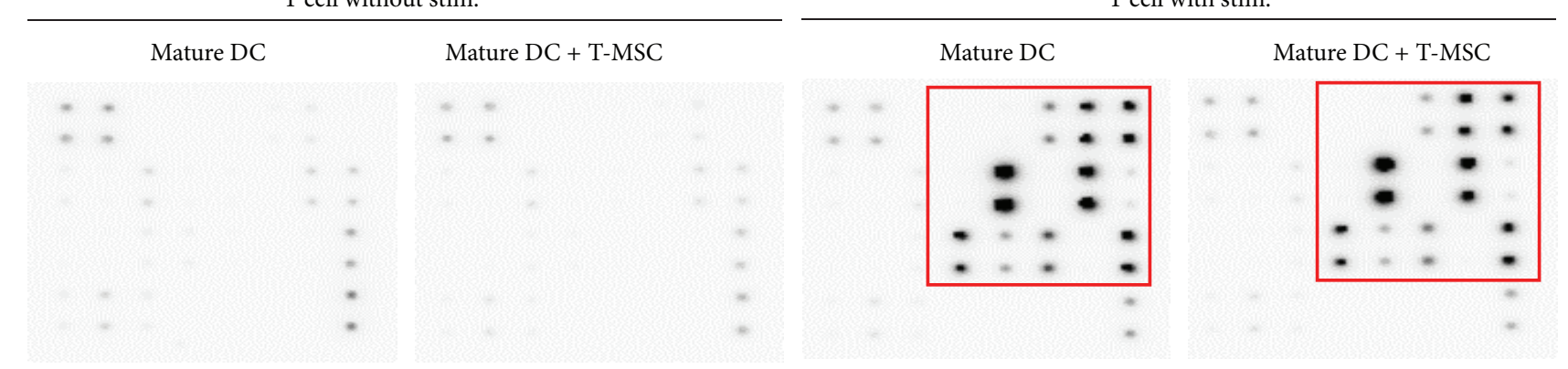

(b)
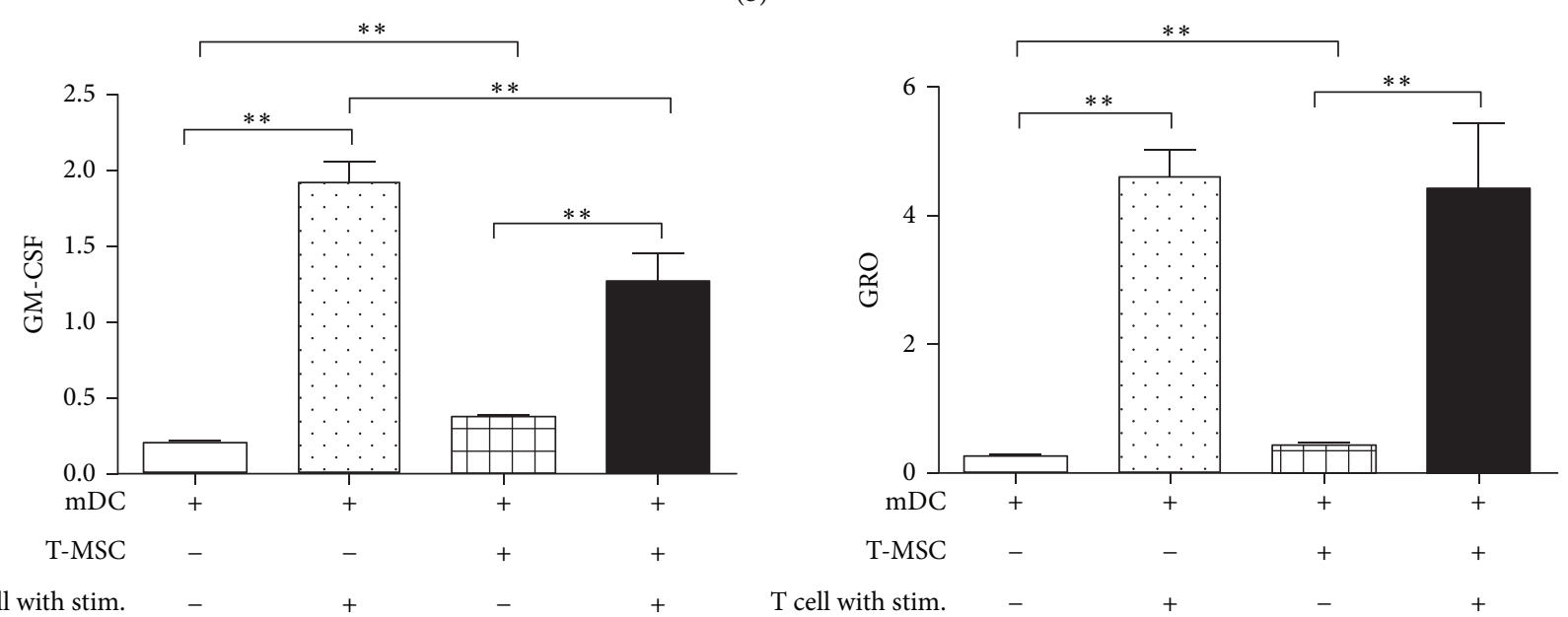

$\mathrm{T}$ cell with stim.

$+$

T cell with stim.

Figure 4: Continued. 

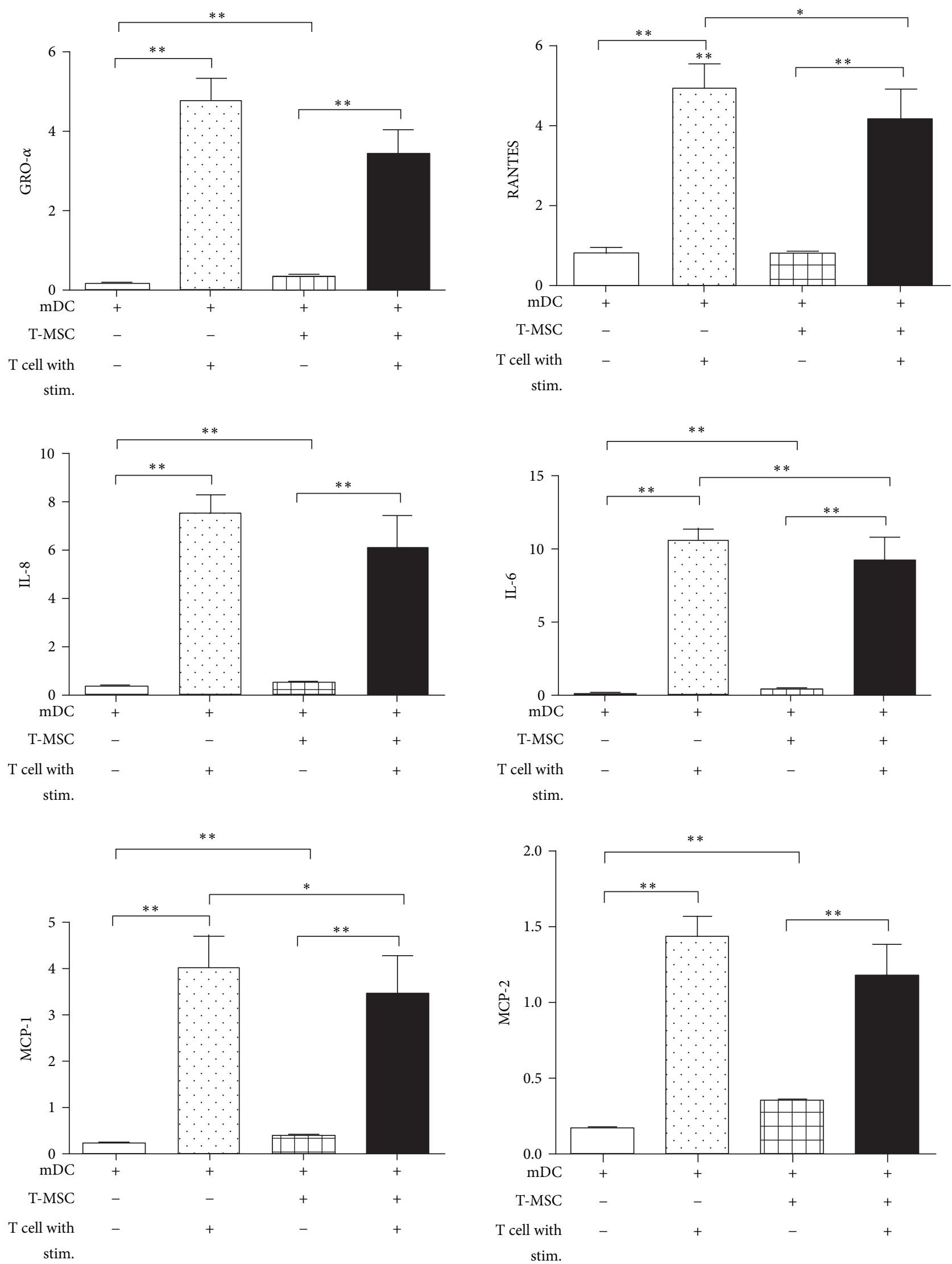

Figure 4: Continued. 


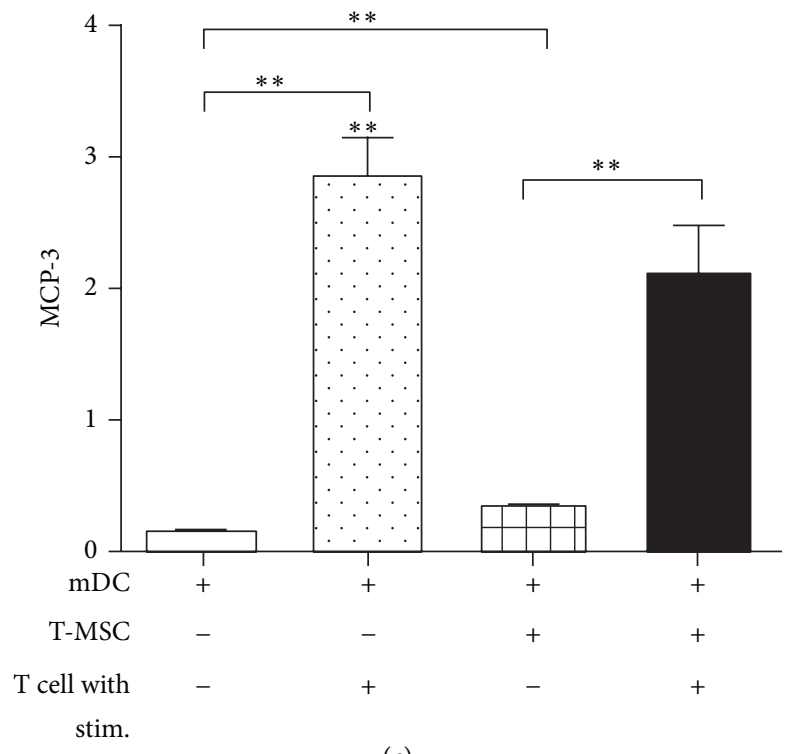

(c)

FIgURE 4: T-MSCs inhibited the release of GM-CSF, IL-6, MCP-1, and RANTES from mature DCs. (a) T cells were cocultured with mature DCs in the presence of T-MSCs. Conditioned medium was collected and subjected to Cytokine Array. (b) Plate arrangement of the Cytokine Array and cytokine spots, which show increased expression, are highlighted with a red box. (c) Expression changes were quantified and significant decreases in GM-CSF, RANTES, interleukin-6 (IL-6), and monocyte chemoattractant protein-1 (MCP-1) were observed when mature DCs and T cells were cocultured with T-MSCs.

and differentiation via the secretome derived from T-MSCs. This finding suggests that T-MSCs possess immunosuppressive effects on DCs, which could be exploited as a cell therapy for immune-mediated disease.

\section{Conflict of Interests}

The authors declare that there is no financial conflict of interests regarding the publication of this paper.

\section{Authors' Contribution}

Minhwa Park was responsible for the experiments, interpretation of the data, and preparation of the paper. Yu-Hee Kim was interpreting the data and editing of the paper. Jung-Hwa Ryu has carried out T-MSC culture and FACS analysis. SoYoun Woo designed the experiments and preparation of the paper. Kyung-Ha Ryu was responsible for conception, design of experiments, and editing of the paper.

\section{Acknowledgment}

This work was supported by the Basic Science Research Program through the National Research Foundation of Korea, which was funded by the Ministry of Education, Science, and Technology (NRF-2012M3A9C6049823).

\section{References}

[1] M. Shi, Z. W. Liu, and F. S. Wang, "Immunomodulatory properties and therapeutic application of mesenchymal stem cells," Clinical and Experimental Immunology, vol. 164, no. 1, pp. $1-8,2011$.

[2] M. Krampera, S. Glennie, J. Dyson et al., "Bone marrow mesenchymal stem cells inhibit the response of naive and memory antigen-specific T cells to their cognate peptide," Blood, vol. 101, no. 9, pp. 3722-3729, 2003.

[3] W. T. Tse, J. D. Pendleton, W. M. Beyer, M. C. Egalka, and E. C. Guinan, "Suppression of allogeneic T-cell proliferation by human marrow stromal cells: implications in transplantation," Transplantation, vol. 75, no. 3, pp. 389-397, 2003.

[4] M. di Nicola, C. Carlo-Stella, M. Magni et al., "Human bone marrow stromal cells suppress T-lymphocyte proliferation induced by cellular or nonspecific mitogenic stimuli," Blood, vol. 99, no. 10, pp. 3838-3843, 2002.

[5] G. M. Spaggiari, A. Capobianco, S. Becchetti, M. C. Mingari, and L. Moretta, "Mesenchymal stem cell-natural killer cell interactions: evidence that activated NK cells are capable of killing MSCs, whereas MSCs can inhibit IL-2-induced NK-cell proliferation," Blood, vol. 107, no. 4, pp. 1484-1490, 2006.

[6] Y.-J. Jung, S.-Y. Ju, E.-S. Yoo et al., "MSC-DC interactions: MSC inhibit maturation and migration of BM-derived DC," Cytotherapy, vol. 9, no. 5, pp. 451-458, 2007.

[7] K. H. Ryu, K. A. Cho, H. S. Park et al., "Tonsil-derived mesenchymal stromal cells: evaluation of biologic, immunologic and genetic factors for successful banking," Cytotherapy, vol. 14, no. 10, pp. 1193-1202, 2012.

[8] B. Puissant, C. Barreau, P. Bourin et al., "Immunomodulatory effect of human adipose tissue-derived adult stem cells: comparison with bone marrow mesenchymal stem cells," British Journal of Haematology, vol. 129, no. 1, pp. 118-129, 2005.

[9] E. Gonzalez-Rey, M. A. Gonzalez, N. Varela et al., "Human adipose-derived mesenchymal stem cells reduce inflammatory 
and $\mathrm{T}$ cell responses and induce regulatory $\mathrm{T}$ cells in vitro in rheumatoid arthritis," Annals of the Rheumatic Diseases, vol. 69, no. 1, pp. 241-248, 2010.

[10] P. M. Domínguez and C. Ardavín, "Differentiation and function of mouse monocyte-derived dendritic cells in steady state and inflammation," Immunological Reviews, vol. 234, no. 1, pp. 90104, 2010.

[11] D. Metcalf, N. A. Nicola, S. Mifsud, and L. di Rago, "Receptor clearance obscures the magnitude of granulocyte-macrophage colony-stimulating factor responses in mice to endotoxin or local infections," Blood, vol. 93, no. 5, pp. 1579-1585, 1999.

[12] G. M. Spaggiari, A. Capobianco, H. Abdelrazik, F. Becchetti, M. C. Mingari, and L. Moretta, "Mesenchymal stem cells inhibit natural killer-cell proliferation, cytotoxicity, and cytokine production: role of indoleamine 2,3-dioxygenase and prostaglandin E2," Blood, vol. 111, no. 3, pp. 1327-1333, 2008.

[13] M. M. Duffy, T. Ritter, R. Ceredig, and M. D. Griffin, "Mesenchymal stem cell effects on T-cell effector pathways," Stem Cell Research and Therapy, vol. 2, no. 4, article 34, 2011.

[14] S. Ghannam, J. Pène, G. Torcy-Moquet, C. Jorgensen, and H. Yssel, "Mesenchymal stem cells inhibit human Th17 cell differentiation and function and induce a $\mathrm{T}$ regulatory cell phenotype," The Journal of Immunology, vol. 185, no. 1, pp. 302$312,2010$.

[15] A. Corcione, F. Benvenuto, E. Ferretti et al., "Human mesenchymal stem cells modulate B-cell functions," Blood, vol. 107, no. 1, pp. 367-372, 2006.

[16] S. Asari, S. Itakura, K. Ferreri et al., "Mesenchymal stem cells suppress B-cell terminal differentiation," Experimental Hematology, vol. 37, no. 5, pp. 604-615, 2009.

[17] W.-H. Liu, J.-J. Liu, J. Wu et al., "Novel mechanism of inhibition of dendritic cells maturation by mesenchymal stem cells via interleukin-10 and the JAK1/STAT3 signaling pathway," PLoS ONE, vol. 8, no. 1, Article ID e55487, 2013.

[18] B. Zhang, R. Liu, D. Shi et al., "Mesenchymal stem cells induce mature dendritic cells into a novel Jagged-2 dependent regulatory dendritic cell population," Blood, vol. 113, no. 1, pp. 46-57, 2009.

[19] S. Chiesa, S. Morbelli, S. Morando et al., "Mesenchymal stem cells impair in vivo T-cell priming by dendritic cells," Proceedings of the National Academy of Sciences of the United States of America, vol. 108, no. 42, pp. 17384-17389, 2011.

[20] J. Kim and P. Hematti, "Mesenchymal stem cell-educated macrophages: a novel type of alternatively activated macrophages," Experimental Hematology, vol. 37, no. 12, pp. 1445-1453, 2009.

[21] D.-I. Cho, M. R. Kim, H.-Y. Jeong et al., "Mesenchymal stem cells reciprocally regulate the M1/M2 balance in mouse bone marrow-derived macrophages," Experimental \& Molecular Medicine, vol. 46, no. 1, article e70, 2014.

[22] R. Maccario, M. Podestà, A. Moretta et al., "Interaction of human mesenchymal stem cells with cells involved in alloantigen-specific immune response favors the differentiation of CD4+ T-cell subsets expressing a regulatory/suppressive phenotype," Haematologica, vol. 90, no. 4, pp. 516-525, 2005.

[23] X.-X. Jiang, Y. Zhang, B. Liu et al., "Human mesenchymal stem cells inhibit differentiation and function of monocyte-derived dendritic cells," Blood, vol. 105, no. 10, pp. 4120-4126, 2005.

[24] F. Djouad, L.-M. Charbonnier, C. Bouffi et al., "Mesenchymal stem cells inhibit the differentiation of dendritic cells through an interleukin-6-dependent mechanism," Stem Cells, vol. 25, no. 8, pp. 2025-2032, 2007.
[25] P. A. Valdez, P. J. Vithayathil, B. M. Janelsins, A. L. Shaffer, P. R. Williamson, and S. K. Datta, "Prostaglandin E2 suppresses antifungal immunity by inhibiting interferon regulatory factor 4 function and interleukin-17 expression in T cells," Immunity, vol. 36, no. 4, pp. 668-679, 2012.

[26] B. V. Lugt, A. A. Khan, J. A. Hackney et al., "Transcriptional programming of dendritic cells for enhanced MHC class II antigen presentation," Nature Immunology, vol. 15, no. 2, pp. 161$167,2014$.

[27] G. De Wert and C. Mummery, "Human embryonic stem cells: research, ethics and policy," Human Reproduction, vol. 18, no. 4, pp. 672-682, 2003.

[28] S. P. Medvedev, A. I. Shevchenko, and S. M. Zakian, "Induced pluripotent stem cells: problems and advantages when applying them in regenerative medicine," Acta Naturae, vol. 2, no. 2, pp. 18-28, 2010.

[29] M.-C. Kastrinaki, I. Andreakou, P. Charbord, and H. A. Papadaki, "Isolation of human bone marrow mesenchymal stem cells using different membrane markers: comparison of colony/cloning efficiency, differentiation potential, and molecular profile," Tissue Engineering, Part C: Methods, vol. 14, no. 4, pp. 333-339, 2008.

[30] D. M. Choumerianou, H. Dimitriou, and M. Kalmanti, "Stem cells: promises versus limitations," Tissue Engineering Part B: Reviews, vol. 14, no. 1, pp. 53-60, 2008. 

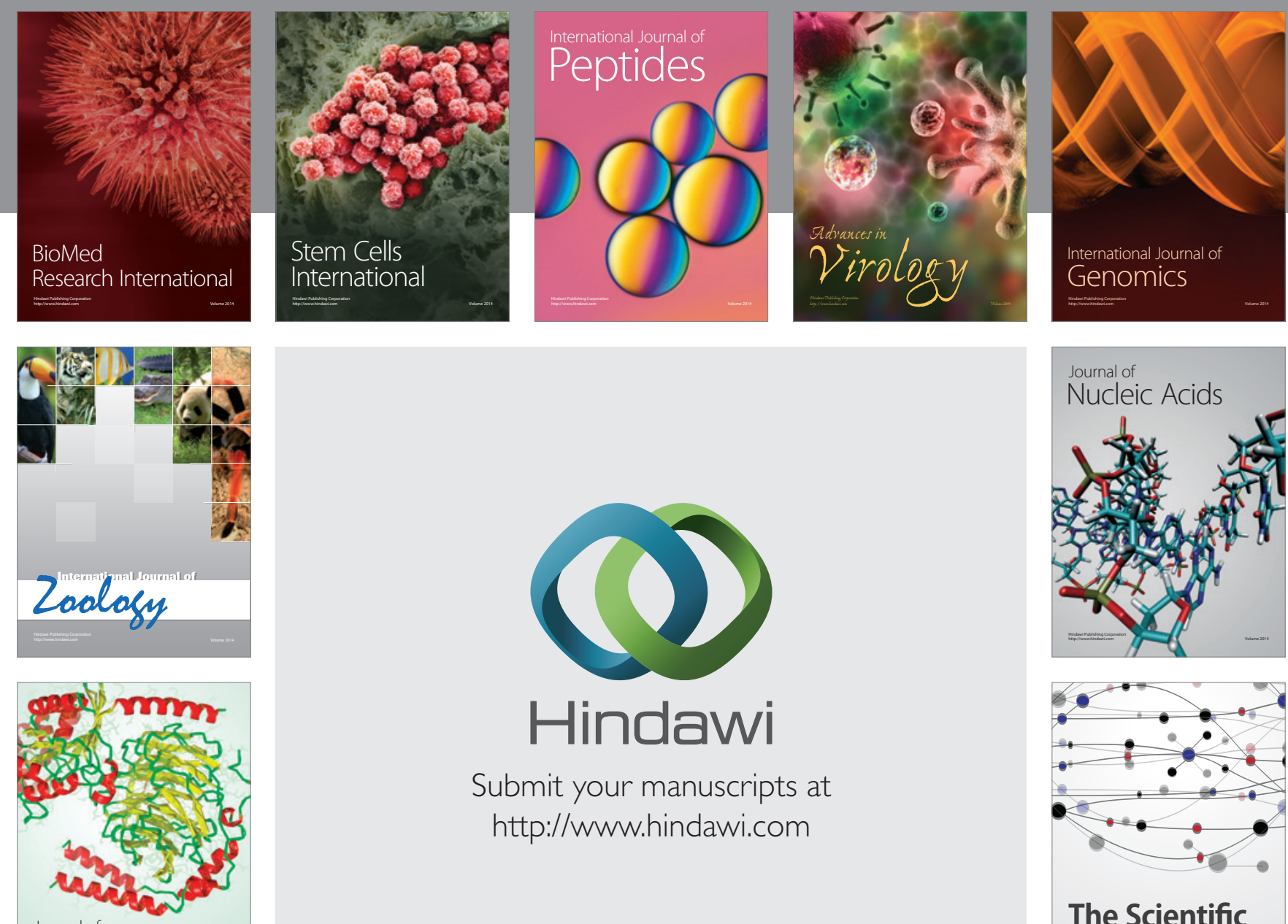

Submit your manuscripts at

http://www.hindawi.com

Journal of
Signal Transduction
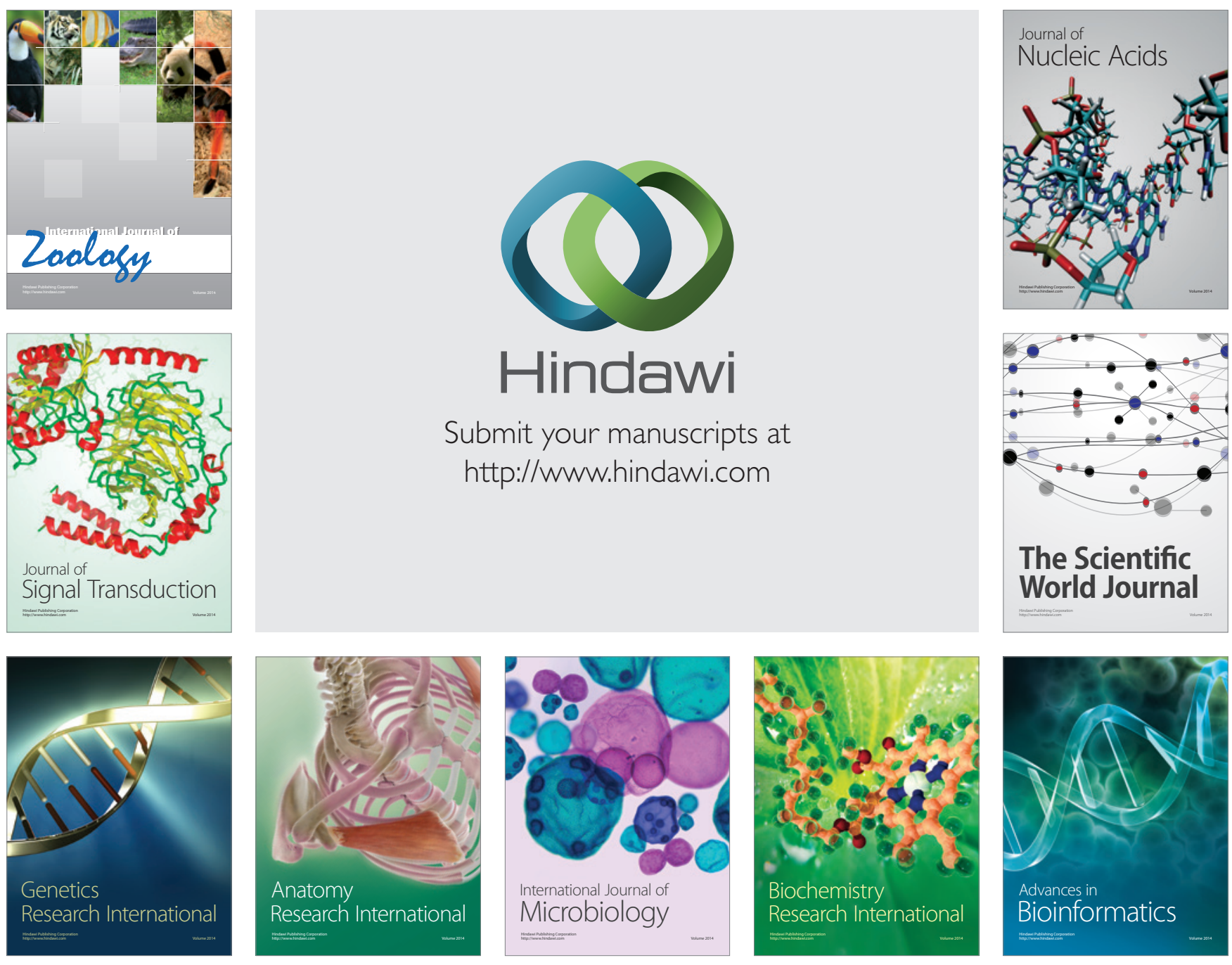

The Scientific World Journal
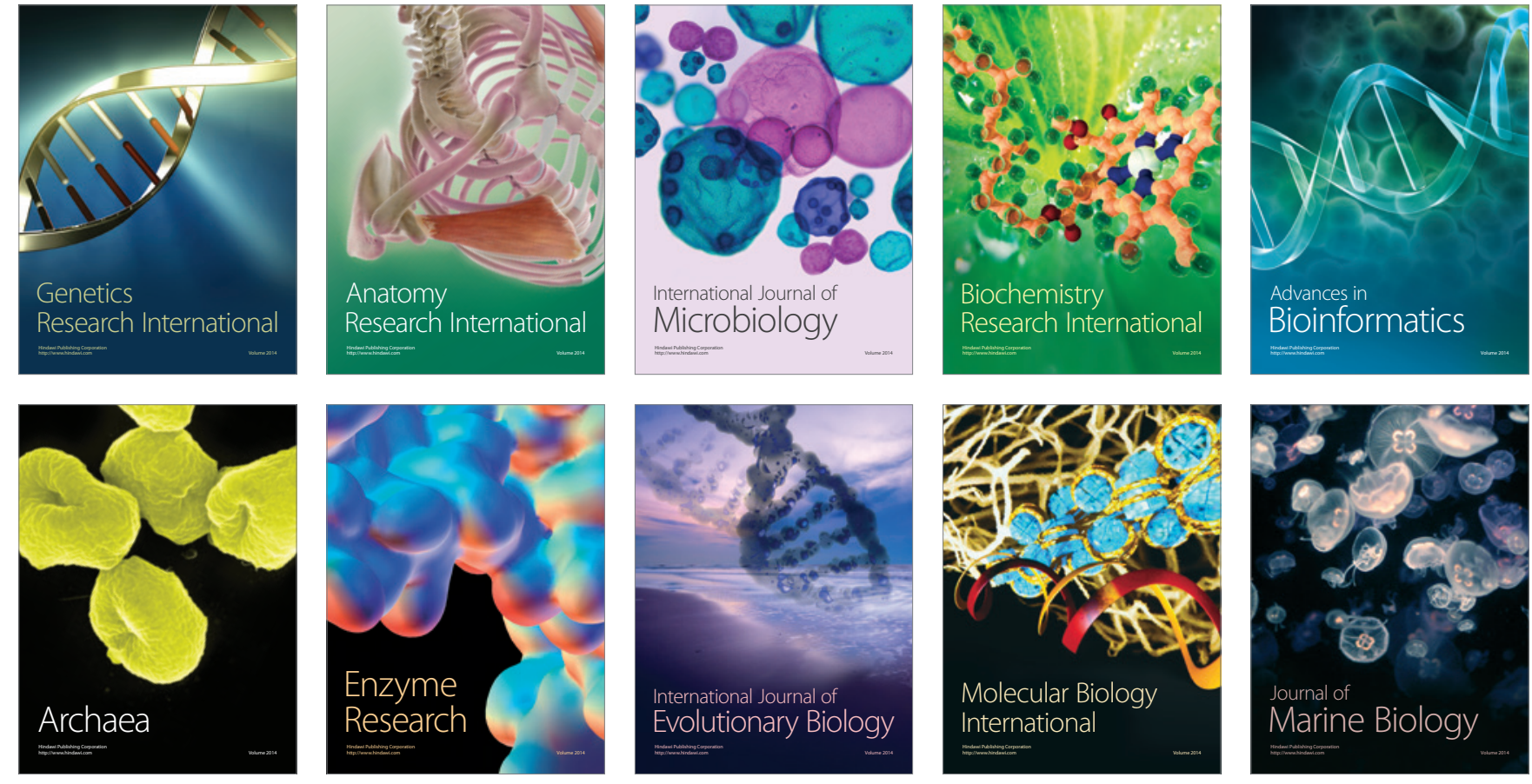